\title{
The Pedagogical Agent in Online Learning: Effects of the Degree of Realism on Achievement in Terms of Gender
}

\author{
Saidatul Maizura Sahimi \\ Farah M. Zain \\ Nabila A. N. Kamar \\ Noorizdayantie Samar \\ Zuraidah A. Rahman \\ Omar Majid \\ Hanafi Atan \\ Fong Soon Fook \\ Universiti Sains Malaysia, Malaysia \\ Wong Su Luan \\ Universiti Putra Malaysia, Malaysia
}

\begin{abstract}
This paper describes the impact of the degrees of realism (unrealistic, moderately realistic and highly realistic) of the pedagogical agent on student's achievement during online learning in terms of gender. Three modes of the e-learning portal with appropriate degrees of realism, namely, Online Learning with a Cartoon Pedagogical Agent (OLCPA), Online Learning with a Moderately Realistic Pedagogical Agent (OLMRPA) and Online Learning with a Highly Realistic Pedagogical Agent (OLHRPA) were developed and implemented. A quasi-experimental 3x2 factorial design was employed; independent variables were three degrees of realism, the dependent variable was achievement scores, and the moderator variable was gender of students. The subjects were 130 Form Four students (16 years old) from Malaysian secondary schools who were randomly assigned to groups. Analysis of variance (ANOVA) was employed to analyze data. The findings of the study suggest that there was no significant difference in the students' achievement among the three degrees of realism in terms of their genders; both genders achieved almost the same across different degrees of realism. The reasons for the observed results are discussed and elaborated.
\end{abstract}

Keywords: Online learning; Pedagogical agent; Degree of realism; Gender issues

\section{Introduction}

Online learning has received tremendous attention among educators due to its potential to support and supplement face-to-face teaching and learning in conventional educational institutions or its use in entirety as in the open and distance learning (ODL) institutions (Rosmayati et al., 2007; Wahyu \& Yahya, 2006). Due to its plethora of the multimedia attributes such as the 
audio, video and animation materials that can be embedded within it, as well as the provision of asynchronous and synchronous collaborations, online learning is seen to be capable of enhancing and facilitating learning (Ashcraft, Treadwell \& Kumar, 2008; Chen, 2007; Stephenson, 2001). In addition, online learning can be conducted anytime and anywhere thus overcoming temporal and spatial limitations and the need to cater to various students' abilities and learning styles as well as enhancing their motivation and satisfaction (Learnframe, 2001; Shea-Schultz \& Fogarty, 2002).

However, several studies show that the effectiveness of online learning is a function of the facilitator and the ensuing depth of the collaboration and discussion that take place between the facilitator and the students (Allen, 2003; Touvinen, 2001). This guidance from the facilitators ensures that students are able to undertake learning tasks smoothly and participate in learning activities effectively (Feham, 2006). There are, however, constraints and limitations in terms of the participation of the facilitator in online collaborations. This is especially so in a course involving a large number of students - this requires the facilitator to be present and provide feedback to all the queries and questions posted in the synchronous and asynchronous tools. These limitations can be overcome to some extent by the presence of the pedagogical agent embedded within the online system. The pedagogical agent acts as a virtual teacher and can take over the role of the facilitator and be able to provide appropriate feedback on each question posted.

\section{Literature Review}

\section{The Pedagogical Agent}

Agent technology has been used widely and in different fields such as in education (Moreno et al., 2001; Rickel \& Johnson, 1999; Slater, 2000) and finance (Cassell et al., 2000). The advancement of virtual reality technology and artificial intelligence has allowed the development of the life-like agent which poses a relatively high degree of interactivity with human beings (Cassell et al., 2000). Clark \& Mayer (2003) clarified that agents can represent a human role both visually and verbally. They can be representations of real people with human characters and human voices or are other artificial characters using appropriate animations and computer-generated voices. A pedagogical agent, on the other hand, plays a role as a tutor or teacher and communicates and collaborates with students in the facilitation of subject contents to produce meaningful learning on the students' part (Atkinson, 2002; Baylor \& Kim, 2004; Clark \& Mayer, 2003; Craig et al., 2002; Moreno et al., 2001; Wang, Chignell \& Ishizuka, 2005).

\section{The Pedagogical Agent's Realism and Learning}

Some studies have looked into the effect of the appearance of the pedagogical agent or the degree of realism of the pedagogical agent on learning. For instance, Baylor \& Kim (2004) looked at the effect of two types of realism in agents (realistic and cartoon) on male and female students. They found that students who used realistic agents exhibited better performance and positive effects compared to students who used the unrealistic agent (cartoon appearance) in their learning. 
Gulz \& Haake (2005) studied students' preferences on the realism of the pedagogical agent. They discovered that most students chose the iconic agent, followed by the moderately realistic and lastly, the highly realistic agent. Moreno et al. (2001) found that the students' usage of highly realistic or unrealistic agents did not exhibit significant differences in the scores of their achievement. Their results showed that a highly realistic image was not always a necessary component for an effective agent in terms of learning (Clark \& Mayer, 2003; Heinich et al., 1993).

\section{Student Gender and the Pedagogical Agent's Realism}

There has not been much research on the degree of realism of the pedagogical agent on student gender and especially in the three degrees of realism - unrealistic, moderately realistic and highly realistic. Baylor \& Kim (2004) reported that male students using the realistic agent learned significantly better than male students using the cartoon (unrealistic) agent. However, no significant difference was observed for female students. In his preference studies, Baylor (2005) found that female students were more likely to choose a cartoon agent (unrealistic) than the male students. While, Gulz \& Haake (2005) found that female students tended to choose iconic agent (unrealistic) relatively higher than male students but not significantly higher.

\section{Level of Realism}

Heinich et al. (1993) stated that the fundamental difference among the visual aspects of the pedagogical agents is the level of realism which they categorised, from cartoon-like (unrealistic) to highly realistic. Baylor (2005) classified realism in two levels as cartoon-like (unrealistic) and realistic; while Gulz \& Haake (2006) classified realism in three levels such as iconic, semi-iconic and realistic. Cartoon-like or iconic images are very simple compared to realistic or naturalistic images which are more complex and appear to look like human beings. Heinich et al. (1993) explained that the more realistic the visual image, the closer it looks like an original appearance.

In this study, the focus is on the three levels of realism of pedagogical agents. These are the cartoon (unrealistic) pedagogical agent, the moderately realistic pedagogical agent, and the highly realistic pedagogical agent. See Figure 1 for samples.

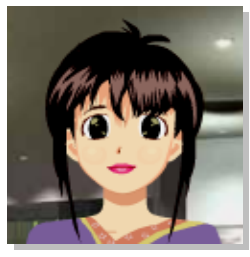

The Cartoon (Unrealistic)

Pedagogical Agent

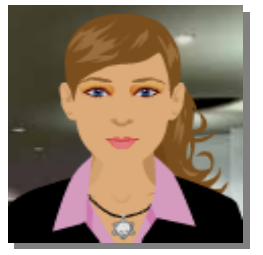

The Moderately Realistic Pedagogical Agent

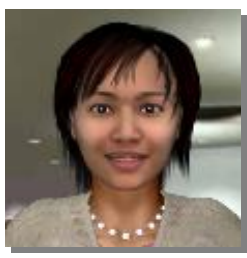

The Highly Realistic Pedagogical Agent

Figure 1. Pedagogical Agents with Three Different Degrees of Realism 


\section{The Theoretical Framework}

The theoretical framework of this research was based on the Realism Theories (Dwyer, 1978), Cognitive Theory of Multimedia Learning, Cognitive Load (Mayer, 2001), Cognitive Load Theory (Sweller, 2003) and the Personalization Principle (Clark \& Mayer, 2003).

Dwyer (1978) explained that the display of visual images is in the form of the realism continuum which delivers information to students. He stressed that learners would face difficulty in identifying important learning cues from more realistic visual stimuli. In a way, he suggested that providing affluent stimuli was not necessarily the most effective way to facilitate students in the learning process. Excessive realism would hinder the learning process. He proposed a curvilinear relationship between the amounts of realism and the extent of a student's achievement.

Heinich et al. (1993) supported this idea and futher suggested that not only would a high degree of realism affect a student's achievement but a lesser degree of realism would do so as well. A high amount of learning takes place when the pedagogical agent poses only a moderately realistic visual appearance (See Figure 2).

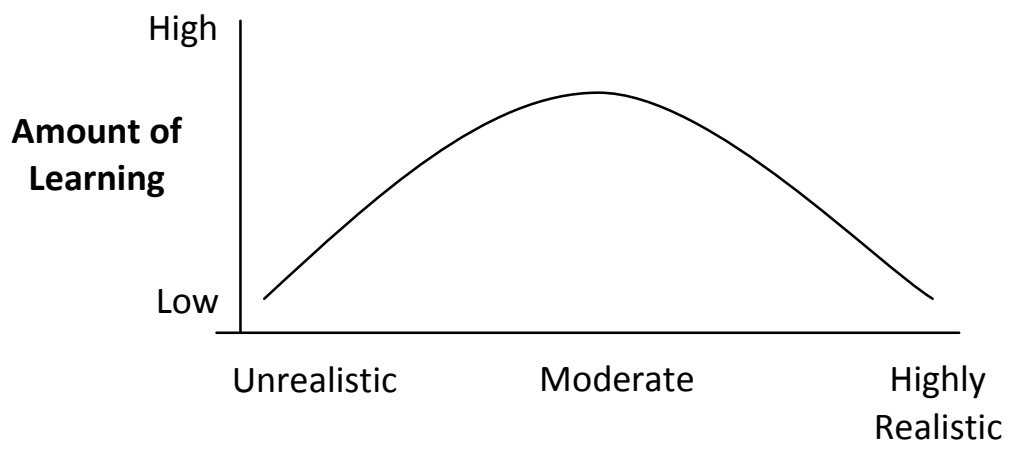

Degrees of Realism

Figure 2. The Curvilinear Relationship between Degrees of Realism and the Amount of Learning (Heinich et al., 1993)

The personalization principle proposes two rules to be used in multimedia learning. The first rule is the use of a conversational rather than a formal style and the second rule is the use of onscreen coaches to promote learning. Clark \& Mayer (2003) explained that students learn better from personalized narration where first and second-person constructions are used in the narration of a script. However, they cautioned against overdoing the personalization style because it would distract students. Another personalization principle is onscreen coaches, which are appropriately called pedagogical agents. A pedagogical agent is used in e-learning to guide students during the learning process. Clark \& Mayer (2003) found that students learn more when they interact with pedagogical agents during the learning. They also suggested that the pedagogical agents may be 
visually realistic or line art figures. When presenting a dialogue, the pedagogical agent should use the natural and conversational form. The pedagogical agent must also serve and act with a valid instructional purpose.

\section{Methodology}

\section{Sample}

The sample of this study consisted of 130 students, 97 males and 33 females, from two different secondary schools (aged 16 years old) taking the O-Level equivalent physic subject at the schools. The samples are divided into three groups with each group being involved in a different treatment (OLCPA, OLMRPA or OLHRPA). They were randomly assigned to any one of the three treatment modes. Each group was exposed either to Online Learning with the Cartoon Pedagogical Agent (OLCPA), Online Learning with the Moderately Realistic Pedagogical Agent (OLMRPA) or Online Learning with the Highly Realistic Pedagogical Agent (OLHRPA).

\section{Framework}

The research framework involved the following independent variables, dependent variables and the moderator variables (shown in Figure 3).

\section{(Independent Variables)}

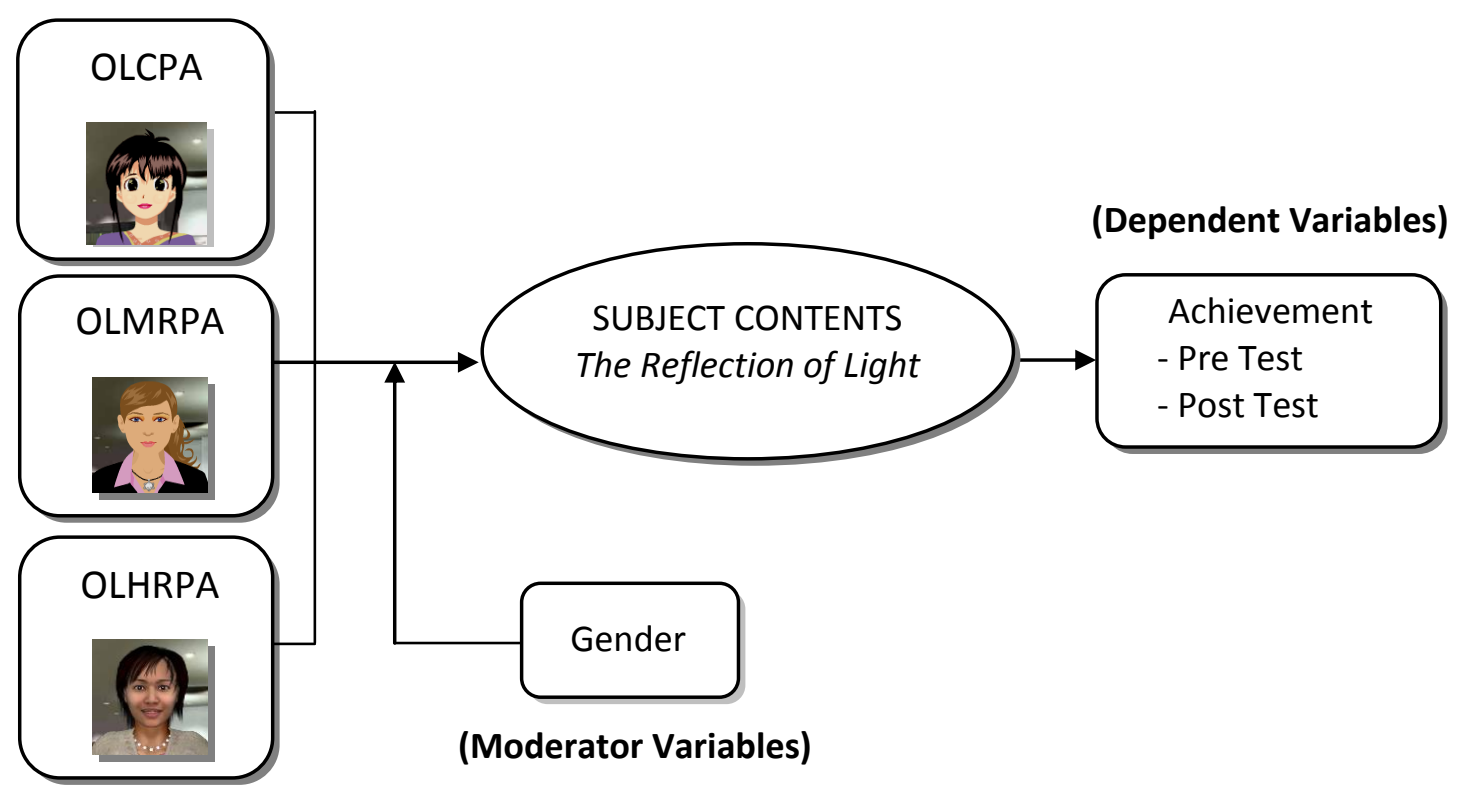

Figure 3. The Research Framework 


\section{Design}

The design of the study was based on a quasi-experimental research that employed a $3 \times 2$ factorial design. It was designed to examine the effects of independent variables on the dependent variables vis-a-vis each of the moderator variables (See Figure 4). The independent variables were the three modes of the pedagogical agent and the dependent variable was the student's achievement. The moderator variable was the gender of the students.

\begin{tabular}{|c|c|c|c|c|}
\hline & & & \multirow{2}{*}{$\begin{array}{l}\text { Male } \\
\text { Female }\end{array}$} & \multirow{2}{*}{ Gender } \\
\hline & & & & \\
\hline Unrealistic & $\begin{array}{c}\text { Moderately } \\
\text { Realistic }\end{array}$ & $\begin{array}{l}\text { Highly } \\
\text { Realistic }\end{array}$ & & \\
\hline \multicolumn{3}{|c|}{ Level of Realism of Pedagogical Agent } & & \\
\hline
\end{tabular}

Figure 4. The 3x2 Quasi-Experimental Design of the Study

\section{Instrumentation}

Data were gathered through two instruments. A pretest and a posttest were used to elucidate achievement scores of students. The pretest and posttest items were similar in content but they differed in sequencing of the questions and their choices. The items were reviewed and validated by two experienced content experts.

\section{Procedures}

This research involved three phases: Phase 1 before the treatment, Phase 2 during the treatment and Phase 3 after the treatment. The activities in Phase 1 were conducted four weeks before the actual treatment. During this phase, the selected students were required to take the Pretest. During Phase 2, the students were exposed to the control treatment. Here, they were exposed to the content on "Light" using the online learning platform embedded with the appropriate pedagogical agent. As stated, the sample had been divided into three groups with each group being assigned to OLCPA, OLMRPA or OLHRPA treatments. During the lesson, the groups were actively guided by their pedagogical agents and they were required to explore the content individually during the entire session. At the end of the session, the Posttest was administered. The three modes of the Online Learning Portal embedded with the appropriate pedagogical agents are shown in Figure 5. 


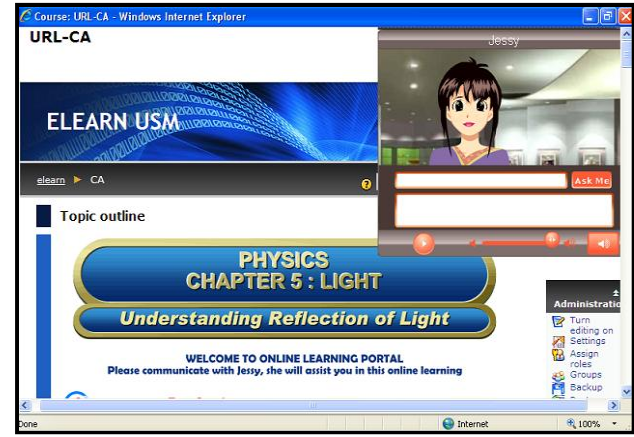

Online Learning with the Cartoon Pedagogical Agent (OLCPA)

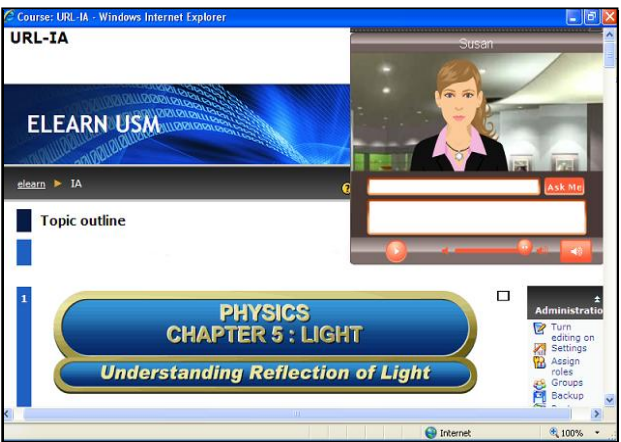

Online Learning with the Moderately Realistic Pedagogical Agent (OLMRPA)

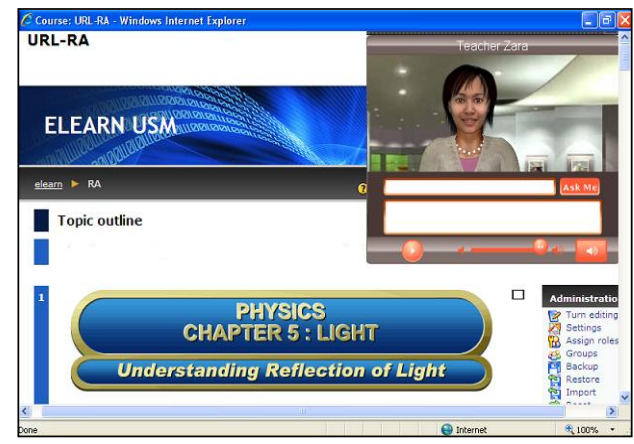

Online Learning with the Highly Realistic Pedagogical Agent (OLHRPA)

Figure 5. Three Modes of Online Learning with the Pedagogical Agents

\section{Findings}

Table 1 shows the mean scores and standard deviations of the achievement for the OLCPA, OLMRPA and OLHRPA modes for both male and female students. The mean score of the students exposed to the OLMRPA mode $(M=27,95 ; S D=14,56)$ was the highest compared to those of the students exposed to the other two modes, OLCRA $(M=22,67 ; S D=14,09)$ and OLHRPA $(M=20,85$; $S D=13,83$ ). 
Table 1. Mean scores for the three modes according to gender

\begin{tabular}{lcccc}
\hline Mode & Gender & Mean & SD & N \\
\hline OLCPA & Male & 22.12 & 14.09 & 33 \\
& Female & 24.17 & 14.59 & 12 \\
\cline { 2 - 5 } & Total & 22.67 & 14.09 & 45 \\
\hline OLMRPA & Male & 27.97 & 13.97 & 37 \\
& Female & 27.86 & 18.68 & 7 \\
\cline { 2 - 5 } & Total & 27.95 & 14.56 & 44 \\
\hline OLHRPA & Male & 22.59 & 14.50 & 27 \\
& Female & 17.50 & 12.21 & 14 \\
\hline Total & Total & 20.85 & 13.83 & 41 \\
& Male & 24.48 & 14.28 & 97 \\
& Female & 22.12 & 14.74 & 33 \\
\hline & Total & 23.88 & 14.38 & 130 \\
\hline
\end{tabular}

Table 2 shows the two-way ANOVA conducted on the students' achievement scores according to the degrees of realism of the pedagogical agent and gender of subjects. There was no significant difference on the main effect for the degrees of realism $[F(2,124)=2.189, p=.116]$. The main effect for gender was not significant either $[F(1,124)=.13, p=.724]$. Finally, the interaction between the degrees of realism of the pedagogical agent and gender of the students also showed no significant difference $[F(2,124)=.59, p=.557]$. In other words, none of the comparisons in the study were turned out to be significant.

Table 2. Two-way ANOVA on students' achievement scores according to degrees of realism of the pedagogical agent and gender of students

\begin{tabular}{lrrrrrr}
\hline \multicolumn{1}{c}{ Source } & $\begin{array}{l}\text { Sum of } \\
\text { Square }\end{array}$ & df & \multicolumn{1}{c}{$\begin{array}{l}\text { Mean of } \\
\text { Square }\end{array}$} & F & Sig. & $\boldsymbol{\eta}^{2}$ \\
\hline Main effects & 889.800 & 2 & 444.900 & 2.188 & .116 & .034 \\
MODE & 25.522 & 1 & 25.522 & .126 & .724 & .001 \\
GENDER & 239.268 & 2 & 119.634 & .588 & .557 & .009 \\
\hline Interaction effects & 25215.030 & 124 & 203.347 & & & \\
MODE*GENDER & 100825.269 & 130 & & & & \\
\hline Error & &
\end{tabular}

\section{Discussion and Conclusion}

This research found that male and female students exposed to OLCPA, OLMRPA or OLHRPA exhibited no significant difference in terms of their achievement. This is contradictory to results of the study by Baylor (2005) who found that female students performed significantly better when using a cartoon agent than male students, whereas male students performed significantly better 
when using the highly realistic pedagogical agent. On the other hand, this finding is supported by a review of empirical research that found the use of pedagogical agents does not generally contribute to improved performance (Dehn \& van Mulken, 2000). It should be noted, however, that Atkinson (2002) found positive effects on performance when animated pedagogical agents were directly embedded within the learning context rather than as a separated talking-head as in this present study.

The results of this study could be explained by the split attention effects (Sweller, 2004). Sweller (2004) found that two sources of redundant information presented concurrently will result in a split-attention. It is apparent the contents were transported through the visual channel while the pedagogical agents were also competing to be transported through the same visual channel into the working memory. This will also result in a higher cognitive load (Moreno and Mayer, 2003) on the working memory and, therefore, impedes the learning process. The pedagogical agents in this study, irrespective of their realism levels, must have negatively "distracted" the students' attention from the contents and could have caused a split attention, resulting in increased cognitive overloads and decreased capacity of the working memory. This condition could have caused a split attention among all the students irrespective of their gender. Hence, there were found to be no significant differences in the performance among the three groups.

This finding is contradictory to the findings of Clark and Mayer (2008). They found that the degree of realism of the pedagogical agent affected the students' achievement, with students using the moderately realistic pedagogical agent attaining a larger amount of learning compared to students using the unrealistic as well as the highly realistic pedagogical agents. The result is also contradictory to the curvilinear relationship between the amounts of realism with the students' achievement as in the theory proposed by Dwyer (1978).

From the practical perspective, the ways in which the pedagogical agent maximizes its effects to facilitate learning still require further investigation. It is critical to consider multimedia design from the perspectives of the cognitive psychology and instructional design while embedding the pedagogical agent. The development of a pedagogical agent can embrace more advantages in various domains and provide more benefits to learners. It is generally suggested that pedagogical agents of different realism levels serve as an important and powerful interface between the learners and the contents. Therefore, Instructional designers and content experts need to be cautious in considering and deciding on the proper use of the pedagogical agents in accordance with the split-attention effects and cognitive overloads.

\section{References}

Allen, M. (2003). Guide to e-learning: Building interactive, fun and effective learning programs for any company: John Wiley \& Sons.

Ashcraft, D., Treadwell, T., \& Kumar, V. K. (2008). Collaborative online learning: A constructivist example. Malaysian Online Journal of Instructional Technology, 4(1), 109-117.

Atkinson, R. K. (2002). Optimizing learning from examples using animated pedagogical agents. Journal of Educational Psychology, 94(2), 416-427. 
Baylor, A. L. (2005). The impact of pedagogical agent image on affective outcomes. Paper presented at the International Conference on Intelligent User Interfaces. San Diego, CA.

Baylor, A. L., \& Kim, Y. (2004). Pedagogical agent design: The impact of agent realism, gender, ethnicity and instructional role. Paper presented at the International Conference on Intelligent Tutoring Systems. Maceio, Brazil.

Cassell, J., Sullivan, J., Prevost, S., \& Churchill, E. (2000). Embodied conversational agents. Cambrige University Press.

Chen, S.-J. (2007). Instructional design strategies for intensive online course: An objectivist blended approach. Journal of Interactive Online Learning, 6(1), 72-86.

Clark, R. C., \& Mayer, R. E. (2003). E-learning and the science of instruction proven guidelines for consumers and designers of multimedia learning. John Wiley \& Sons.

Craig, S. D., Gholson, B., \& Driscoll, D. M. (2002). Animated pedagogical agents in multimedia educational environments: Effects of agent properties, picture features and redundancy. Journal of Educational Psychology, 94(2), 428-434.

Debn, D. M., \& van Mulken, S. (2000). The impact of animated interface agents: A review of empirical research. International Journal of Human-Computer Studies, 52(1), 1-22.

Dwyer, F. M. (1972). A guide for improving visualized instruction. Learning Services.

Gulz, A., \& Haake, M. (2005). Social and visual style in virtual pedagoical agents. Paper presented at the In: Workshop Proceedings: Adapting the Interaction Style to Affective Factors, in conjuction with the 10th International Conference on User Modelling (UM'05), Edinburg, Scotland.

Gulz, A., \& Haake, M. (2006). Design of animated pedagogical agents - A look at their look. International Journal of Human-Computer Studies, 64(4), 322-339.

Heinich, R., Molenda, M., \& Russell, J. D. (1993). Instructional media and the new technology of instruction. Macmillan.

Learnframe. (2001). E-learning vs. online learning. From http://www.learnframe.com/aboutelearning/page4.asp

Mohd Feham, M. G. M. Z. (2006). Design, development and evaluation of a web courseware with a pedagogical agent. Universiti Sains Malaysia, Malaysia.

Moreno, R., Mayer, R. E., Spires, H. A., \& Lester, J. C. (2001). The case for social agency in computer-based teaching: Do students learn more deeply when they interact with animated pedagogical agents? Cognition and Instruction, 19(2), 177-213.

Rickel, J., \& Johnson, W. L. (1999). Animated agents for procedural training in virtual reality: Perception, cognition and motor control. Applied Artificial Intelligence, 13, 343-382.

Rosmayati, M., Zuriana, A. B., \& Mohd Sabri, A. (2007). Development of online teaching and learning modules. Paper presented at the 1st International Malaysian Educational Technology Convention.

Shea-Schultz, H., \& Fogarty, J. (2002). Online learning today strategies that work. Berrett-Koehler. 
Slater, D. (2000). Interactive animated pedagogical agents: Mixing the best of human and computer-based tutors. From http://Idt.stanford.edu/ slater/media/slater_masters_project_final_report.pdf

Stephenson, J. (2001). Teaching and learning online pedagogies for new technologies. Kogan Page.

Sweller, J. (2004). Instructional design consequences of an analogy between evolution by natural selection and human cognitive architecture. Instructional Science, 32(1-2), 9-31

Touvinen, J. E. (2001). Implications of discovery learning research for the design of flexible learning. Paper presented at the ASET-HERDSA 2000 Conference, Toowoomba, Qld.

Wahyu, I., \& Yahya, B. (2006). Aplikasi 'e-learning' dalam Pengajaran dan Pembelajaran di SekolahSekolah Malaysia: Isu dan cadangan perlaksanaanya. Paper presented at the Seminar TVE06.

Wang, H., Chignell, M., \& Ishizuka, M. (2005). Improving the usability and effectiveness of online learning: How can avatars help? from http://www.noahx.com/resources/wang-HFES05.pdf

Correspondence: Hanafi Atan, School of Distance Education, Universiti Sains Malaysia, 11800 Pulau Pinang, Malaysia. 